Article

\title{
The Effect of Chrysin-Loaded Phytosomes on Insulin Resistance and Blood Sugar Control in Type 2 Diabetic db/db Mice
}

\author{
Seong-min Kim and Jee-Young Imm * \\ Department of Foods and Nutrition, Kookmin University, Seoul 02707, Korea; ksm618@nate.com \\ * Correspondence: jyimm@kookmin.ac.kr; Tel.: +82-10-2526-1219
}

Received: 27 October 2020; Accepted: 23 November 2020; Published: 24 November 2020

check for updates

\begin{abstract}
Although a variety of beneficial health effects of natural flavonoids, including chrysin, has been suggested, poor solubility and bioavailability limit their practical use. As a promising delivery system, chrysin-loaded phytosomes (CPs) were prepared using egg phospholipid (EPL) at a 1:3 molar ratio and its antidiabetic effects were assessed in $\mathrm{db} / \mathrm{db}$ diabetic mice. Male C57BLKS/J-db/db mice were fed a normal diet (control), chrysin diet (100 mg chrysin $/ \mathrm{kg}), \mathrm{CP} \operatorname{diet}(100 \mathrm{mg}$ chrysin equivalent $/ \mathrm{kg})$, metformin diet $(200 \mathrm{mg} / \mathrm{kg}$ ) or EPL diet (vehicle, the same amount of EPL used for CP preparation) for 9 weeks. Administration of CP significantly decreased fasting blood glucose and insulin levels in $\mathrm{db} / \mathrm{db}$ mice compared with the control. An oral glucose tolerance test and homeostatic model assessment for insulin resistance were significantly improved in the CP group $(p<0.05)$. CP treatment suppressed gluconeogenesis via downregulation of phosphoenolpyruvate carboxykinase while it promoted glucose uptake in the skeletal muscle and liver of $\mathrm{db} / \mathrm{db}$ mice $(p<0.05)$. The CP-mediated improved glucose utilization in the muscle was confirmed by upregulation of glucose transporter type 4 , hexokinase 2 and peroxisome proliferator-activated receptor $\gamma$ during treatment $(p<0.05)$. The CP-induced promotion of GLUT4 plasma translocation was confirmed in the skeletal muscle of $\mathrm{db} / \mathrm{db}$ mice $(p<0.05)$. Based on the results, CP showed greater antidiabetic performance compared to the control by ameliorating insulin resistance in $\mathrm{db} / \mathrm{db}$ mice and phytosome can be used as an effective antidiabetic agent.
\end{abstract}

Keywords: chrysin; phytosome; blood sugar control; C57BLKS/J-db/db mice; insulin resistance

\section{Introduction}

Diabetes mellitus (DM) is a metabolic disorder characterized by chronic hyperglycemia. Impairment of insulin secretion, increased glucose hepatic output, and decreased insulin sensitivity are responsible for DM [1]. Type $1 \mathrm{DM}$ is caused by destruction of the insulin producing pancreatic $\beta$-cell islet while insulin resistance is the main cause for type $2 \mathrm{DM}$. Most diabetic patients are type 2 $\mathrm{DM}$ and it is becoming an emerging global health concern [2]. Genetic predisposition, obesity, and lack of exercise are major risk factors for type $2 \mathrm{DM}$. The pancreatic $\beta$-cell increases insulin production for glucose disposal in the early stage of insulin resistance; however, extended hyperglycemic conditions eventually lead to type 2 DM [3].

Flavonoids are plant metabolites that are abundantly found in the human diet. Consumption of flavonoids, especially anthocyanins, lowered risk of type 2 DM in the US population [4] and the consumption of flavone and flavonols was inversely correlated with insulin resistance in the 2007-2009 Korea National Health and Nutritional Examination surveys [5]. Chemically, flavonoids consist of two aromatic rings (A and $\mathrm{B}$ ) linked by an oxygenated three carbon heterocyclic ring $(\mathrm{C})$. The number and 
location of hydroxylation, methoxylation and glycosylation in flavonoids critically influences their bioactivity [6].

Chrysin (5,7-dihydroxyflavone) is a natural flavonoid distributed in plants and often found in bee propolis and flowers. Chrysin treatment for 16 weeks significantly reduced renal inflammation by the suppression of renal TNF- $\alpha$ production and NF- $\mathrm{kB}$ nuclear translocation in high-fat diet and streptozotocin-induced type $2 \mathrm{DM}$ rats. The reduction in inflammation and oxidative stress due to chrysin treatment resulted in the restoration of renal function [7]. The administration of chrysin (30 and $100 \mathrm{mg} / \mathrm{kg}$ for 26 days) in Streptozotocin-induced diabetic rats resulted in decreased blood glucose levels and inflammatory cytokine production in the cerebral cortex and hippocampus [8]. Chrysin treatment also ameliorated STZ-induced hypertension and vascular complications [9]. Chrysin administration $(100 \mathrm{mg} / \mathrm{kg}$, 18 weeks) was able to attenuate fructose-induced metabolic syndrome, such as hypertension, hepatic fibrosis, and hyperinsulinemia, but serum leptin and hepatic TG levels remained unchanged [10]. In addition, it has been reported that chrysin exerts neuroprotective effects by increasing the dopamine levels in the brain in 6-hydroxydopamine-induced neurodegenerative Parkinson's disease mice [11].

The effect of dietary flavonoids is still not conclusive even though the evidence regarding health benefits of flavonoid intake is increasing [12]. This is partly due to the low absorption and fast clearance of flavonoids in the body. Most orally administered chrysin $(400 \mathrm{mg})$ was excreted in feces and only a minor portion was detected in urine as chrysin glucuronide (2-26 mg) or chrysin (0.2-3.1 mg), based on the result of a bioavailability study with seven healthy volunteers [13]. Regarding the effect of chrysin on the intestinal environment and microbiome, the administration of chrysin $(100 \mathrm{mg} / \mathrm{kg}$, 18 weeks) decreased high fructose-mediated upregulated GLUT5 mRNA expression but did not improve dysbiosis in rats [14]. Poor solubility and short circulation half-life lowered the bioavailability of chrysin. Thus, an efficient delivery system is required to enhance the low bioavailability of chrysin.

Phytosomes refers to the molecular complexation between phytochemical constituents and phospholipids [15]. Typically, polyphenolic compounds are present as an integral part of phospholipid membrane in phytosomes and display better pharmacological performance compared to liposomes containing polyphenolic constituents in their inner cavity [16]. Rani et al. [17] has reported that the phytosome of Casuarina equisetifolia extract containing chrysin improved antidiabetic and antihyperlipidemic activities in Wistar rats.

In our previous study, stable (zeta potential $-31 \mathrm{mV}$; polydispersity index 0.29 ) and uniform nano-sized chrysin-loaded phytosomes (CPs) with an average particle size of $117 \mathrm{~nm}$ were produced using egg phospholipid (EPL). We confirmed that CP promoted glucose uptake by upregulating GLUT4 and PPAR $\gamma$ gene expression in $\mathrm{C} 2 \mathrm{C} 12$ myotubes [18]. As a continuation, the previous study effects of $\mathrm{CP}$ on insulin resistance and blood sugar control were examined in type 2 diabetic $\mathrm{db} / \mathrm{db}$ mice.

\section{Results and Discussion}

\subsection{Effect of CP Supplementation on Blood Biochemical Makers}

C57BL/KsJ-db/db mice have been widely used as a model of DM and this strain displays increased leptin and insulin level as well as high plasma cholesterol [19]. In our 9 week feeding trial, the animals were randomly divided into six groups: (1) $\mathrm{m}+/ \mathrm{db},(2) \mathrm{db} / \mathrm{db}$ control group (control), (3) positive control group (metformin), (4) db/db + chrysin group (chrysin), (5) db/db + CP (CP), and (6) db/db + vehicle group (vehicle). No significant difference was found in initial and final body weight among all $\mathrm{db} / \mathrm{db}$ groups after completing feeding trial (data not shown). The blood biochemical makers of each experimental group are listed in Table 1. The level of alanine aminotransferase (ALT), the liver inflammation marker, tends to decrease in the CP group $(0.1<p<0.05)$. ALT has greater specificity for detecting liver injury than aspartate aminotransferase (AST) since ALT is mainly localized in the hepatocytes while AST is present in various tissues such as the liver, muscles, and kidneys [20]. Sirovina et al. [21] reported that the intraperitoneal injection of chrysin $(50 \mathrm{mg} / \mathrm{kg}, 7$ days) in alloxan-induced 
diabetic mice alleviated liver damage; however, no indication of the hepatoprotective effects of chrysin were found in this study.

Table 1. Effect of CP administration on blood biochemical parameters.

\begin{tabular}{ccccccc}
\hline Group & $\mathbf{m + / d b}$ & Control & Metformin & Chrysin & CP & Vehicle \\
\hline ALT (U/L) & $43 \pm 14$ & $120 \pm 35$ & $85 \pm 32$ & $139 \pm 38$ & $77 \pm 23$ & $88 \pm 39$ \\
AST (U/L) & $87 \pm 27$ & $183 \pm 53$ & $136 \pm 47$ & $193 \pm 26$ & $129 \pm 26$ & $140 \pm 42$ \\
TG (mg/dL) & $126 \pm 16$ & $288 \pm 6$ & $257 \pm 93$ & $392 \pm 83$ & $195 \pm 76$ & $140 \pm 29 *$ \\
TC (mg/dL) & $103 \pm 11$ & $132 \pm 15$ & $131 \pm 15$ & $116 \pm 14$ & $113 \pm 15^{*}$ & $107 \pm 18^{*}$ \\
HDL-c (mg/dL) & $80 \pm 9$ & $96 \pm 7$ & $93 \pm 9$ & $85 \pm 15$ & $90 \pm 14$ & $82 \pm 12$ \\
LDL-c (mg/dL) & $49 \pm 8$ & $93 \pm 10$ & $90 \pm 18$ & $105 \pm 18$ & $62 \pm 18^{*}$ & $52 \pm 16^{* *}$ \\
Leptin (ng/mL) & $1.2 \pm 0.9$ & $22 \pm 7$ & $26 \pm 9$ & $23 \pm 11$ & $18 \pm 5$ & $21 \pm 9$ \\
HbA1c (\%) & $4.6 \pm 0.2$ & $12.0 \pm 2.1$ & $9.0 \pm 2.1 *$ & $10.4 \pm 2.4$ & $9.8 \pm 0.4$ & $9.4 \pm 0.6$ \\
\hline
\end{tabular}

$\mathrm{CP}$, chrysin-loaded phytosomes; ALT, alanine aminotransferase; AST, aspartate aminotransferase; TG, triacylglycerol; TC, total cholesterol; HDL-c, high-density lipoprotein cholesterol; LDL-c, low-density lipoprotein. Each value represents mean \pm standard error $(n=8) .{ }^{*} p<0.05,{ }^{* *} p<0.01$ compared with the control group.

Serum total cholesterol (TC) and low-density lipoprotein cholesterol (LDL-c) concentrations were significantly decreased in the CP group $(p<0.05)$. In addition, Triacylglycerol (TG), TC and LDLc levels were reduced in the vehicle group. The latter observation is in line with the observation by Lee et al. [22], who reported that administration of phosphatidylcholine reduced TG and TC levels in a high fat diet-induced obesity mice model. EPL consists of phosphatidylcholine (84.5\%), phosphatidyl-ethanolamine (9\%), and sphingomyelin (3\%). Dietary PC also significantly lowered intestinal cholesterol absorption in rat and egg PC was more effective than soy PC [23]. The greater proportion of long-chain saturated fatty acid in egg PC could be associated with greater potency. The beneficial effect of dietary sphingomyelin either from milk or egg on lipid metabolism was reported in high-fat diet-fed mice [24].

No significant differences were found in serum leptin levels among experimental groups even though leptin is known to be related to body fat mass and insulin resistance [25]. Dietary chrysin supplementation did not decrease fat mass, serum leptin, or insulin levels in azoxymethane-induced colon carcinogenic mice [19]. The level of glycated hemoglobin (HbA1c) in the metformin group decreased significantly $(p<0.05)$. HbA1c reflects the extent of erythrocyte glycation accumulated over 2-3 months. Thus, $\mathrm{HbA1c}$ has been used for the evaluation of long-term glycemic control [26]. Considering that $\mathrm{HbA} 1 \mathrm{c}$ reflects the interaction between protein and glucose, it can probably predict the risk of diabetic complications better than other glycemic control makers such as fasting plasma glucose and oral glucose tolerance test (OGTT) [27]. We are not sure about the exact reasons for the lack of statistical significance in $\mathrm{HbA} 1 \mathrm{c}$ between control and $\mathrm{CP}$ group, but it may be ascribed to insufficient dosage or high biological variation in $\mathrm{HbA1c}$.

\subsection{Effect of CP on Insulin Resistance}

The fasting blood glucose level (FBG) of the control group increased by five times with the $\mathrm{m}+\mathrm{db}$ group after 9 weeks. The administration of metformin and CP significantly lowered FBG (Figure 1; $p<0.05)$ but no change was found in chrysin group. All treatment groups displayed significant differences in serum insulin levels. Homeostasis model assessment of insulin resistance (HOMA-IR) was calculated to evaluate samples contribution to insulin resistance. HOMA-IR improvement was found in the metformin, chrysin and CP groups compared to the control group $(p<0.05)$. This result indicates that insulin sensitivity was effectively improved by $\mathrm{CP}$ rather than by chrysin supplementation. 


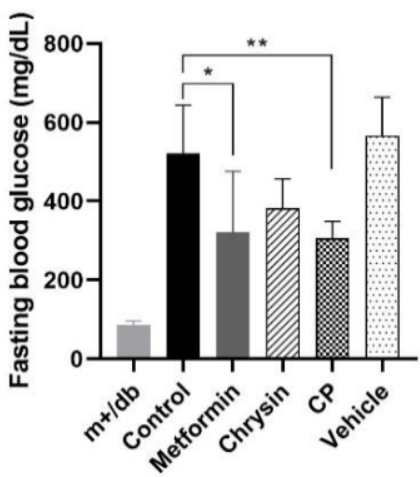

(A)

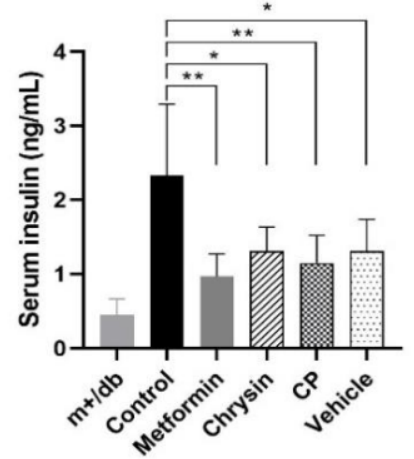

(B)

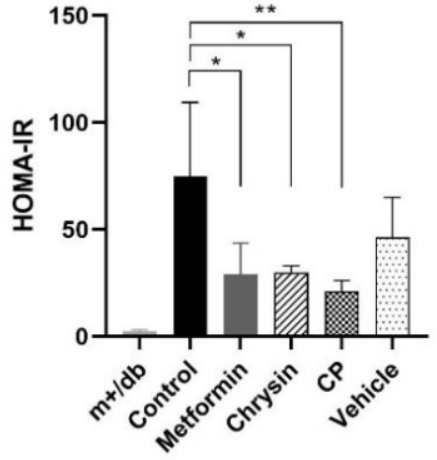

(C)

Figure 1. The effects of CP on (A) blood glucose, (B) serum insulin and (C) HOMA-IR. CP, chrysin-loaded phytosomes; HOMA-IR, homeostasis model assessment of insulin resistance. Each value represents mean \pm standard error $(n=8) .{ }^{*} p<0.05,{ }^{* *} p<0.01$ compared with control group.

The OGTT is widely used to evaluate an animal's ability to control blood glucose. The rate of blood glucose disappearance was accelerated when metformin or $\mathrm{CP}$ was administrated to $\mathrm{db} / \mathrm{db}$ mice (Figure 2A) and glucose tolerance expressed as the area under the curve (AUC) was significantly improved in the metformin and $\mathrm{CP}$ groups (Figure $2 \mathrm{~B}, p<0.05$ ). There are no clear-cut criteria for diagnosing insulin resistance and some discrepancy was noticed in the biomarkers for insulin resistance such as FBG, HOMA-IR, and HbA1c. The metformin group exhibited consistent improvements in all three biomarkers, while the CP group displayed significant difference in both FBG and HOMA-IR. Chrysin treatment failed to show significant differences in FBG and HbA1c. Kang et al. [28] reported that FBG is critically influenced by stressful conditions and food intake while the rate of hemoglobin glycation varied depending on erythrocyte lifespan, iron status, and renal function.

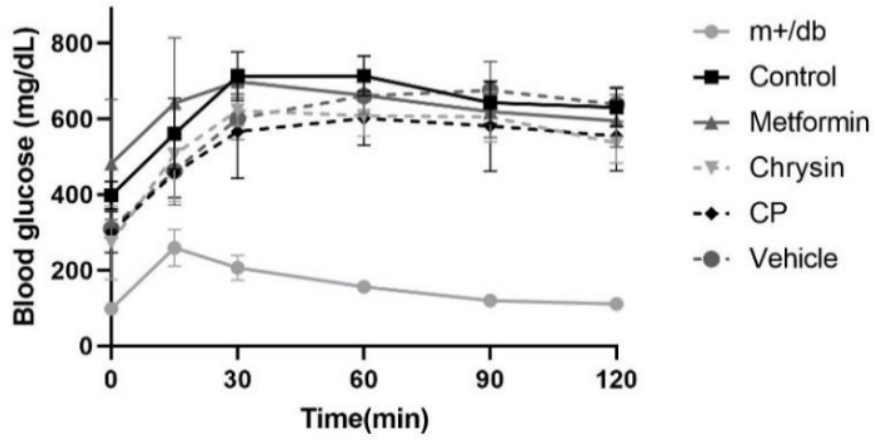

(A)

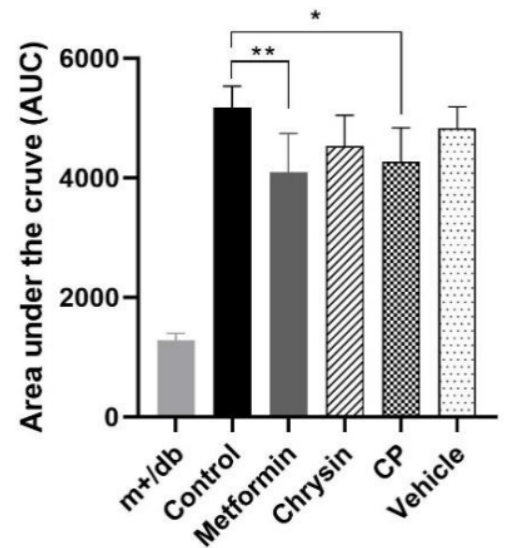

(B)

Figure 2. The effects of CP on (A) OGTT and its (B) AUC. OGTT, oral glucose tolerance test; AUC, area under the curve; $\mathrm{CP}$, chrysin-loaded phytosomes. Each value represents mean \pm standard error $(n=8)$. ${ }^{*} p<0.05,{ }^{* *} p<0.01$ compared with control group.

These results suggest that chrysin bioavailability was increased by the complexation with EPL. Similarly, another study found that silybin, an active flavonoid in milk thistle, increased over 100-fold in plasma when administered as a nanophytosome. Furthermore, pharmacodynamic analysis of rats showed that silybin plasma concentrations increased 1.6 times when administered as a phytosome 
compared with a free silybin mixture [29]. Orally administered quercetin phytosome also improved plasma quercetin absorption in healthy volunteers (18-50 years) up to 20 times [30].

\subsection{Effects of CP on the Glucose Metabolism Related Gene Expression in the Liver}

Insulin resistance and increased hepatic glucose production lead to hyperglycemia in type 2 DM [31]. Gluconeogenesis is considered to be an important parameter of glucose homeostasis and the glucogenic pathway is suppressed by insulin via transcriptional regulation of the gluconeogenesis enzymes, glucose-6-phosphatase (G6Pase) phosphoenolpyruvate carboxykinase (PEPCK) [4,32]. Type 2 DM patients typically display increased hepatic gluconeogenesis. Metformin, one of the most effective drugs in treating type $2 \mathrm{DM}$, significantly reduces hepatic gluconeogenesis without increasing insulin secretion [33]. Thus, the gene expressions of two gluconeogenesis rate-limiting enzymes, G6Pase and PEPCK, are effective molecular targets for treating type 2 DM [32].

Gene expressions of G6Pase and PEPCK were significantly increased in $\mathrm{db} / \mathrm{db}$ mice, reflecting increased glucose output in the liver as shown in Figure 3. The gene expressions of these two enzymes were significantly decreased through metformin treatment $(p<0.05)$ while $\mathrm{CP}$ treatment significantly suppressed only PEPCK expression alone $(p<0.05)$.

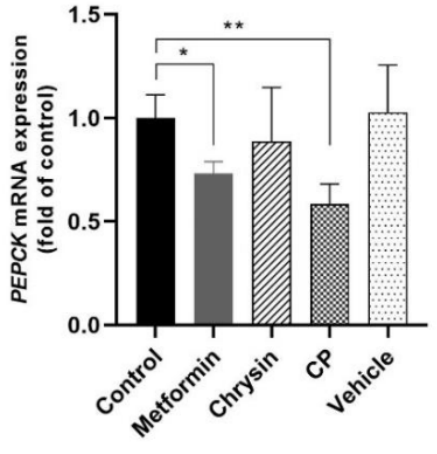

(A)

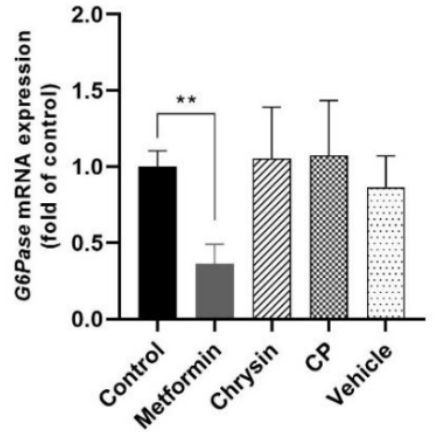

(B)

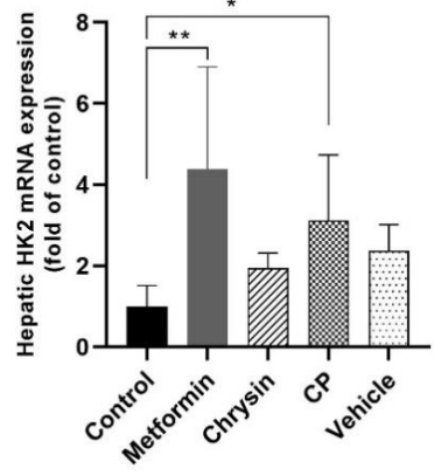

(C)

Figure 3. Effects of $\mathrm{CP}$ on the glucose metabolism related gene expression in the liver of $\mathrm{db} / \mathrm{db}$ mice. (A) PEPCK, (B) G6Pase and (C) HK2. PEPCK, phosphoenolpyruvate carboxykinase; G6Pase, glucose-6-phospatase; HK2, hexokinase; CP, chrysin-loaded phytosomes. Each value represents mean \pm standard error $(n=8) .{ }^{*} p<0.05,{ }^{* *} p<0.01$ compared with control group.

The hepatic HK2 level was significantly decreased in $\mathrm{db} / \mathrm{db}$ mice compared with the $\mathrm{m}+\mathrm{db}$, but it was significantly upregulated by metformin or CP treatment $(p<0.01, p<0.05$, Figure 3C). $\mathrm{Li}$ et al. [34] reported that all $\mathrm{HK}$ isoform (1-4) expressions were significantly reduced in the liver of $\mathrm{db} / \mathrm{db}$ mice. Berberine treatment alleviated hyperglycemia by upregulating all hepatic hexokinase isoforms. We measured HK2 levels since HK2 has greater glucose affinity than other hexokinase isoforms [35]. Hepatic Hk2 gene plays an important role in glucose homeostasis and overexpressed HK2 expression in the liver suggested as an effective pharmacological target for type 2 DM [36]. These results indicate that the hypoglycemic effect of $\mathrm{CP}$ was partly due to suppression of PEPCK and upregulated hepatic HK2 in db/db mice.

PEPCK modulates gluconeogenic flux to glucose-6-phosphate by controlling oxaloacetic acid conversion to phosphoenolpyruvate, while G6Pase regulates the production of free glucose from glucose-6-phosphate [37]. Insulin resistance impairs effective action of insulin on glucogenic enzymes and results in hyperglycemia in type $2 \mathrm{DM}$. Liver-specific insulin-receptor knockout mice (LIRKO) displayed severe glucose intolerance and resulted in increased hepatic glucose production. LIRKO mice showed significantly increased PEPCK and G6Pase expressions in the liver accompanying hyperinsulinemia [38]. 
The supplementation of citrus unshiu peel extract ameliorated hyperglycemia by modulation of hepatic gluconeogenesis in $\mathrm{db} / \mathrm{db}$ mice, similar to the results of this study [39]. Unshiu peel extract significantly suppressed PEPCK mRNA expression without affecting G6Pase and glucokinase expression in the liver. Gluconeogenesis suppression is suggested as a therapeutic target to alleviate type 2 DM Metformin, a positive control used in this study, known as a potent inhibitor of hepatic glucose production [32]. Downregulation of PEPCK by CP contributed to the regulation of glucose homeostasis by modulating the gluconeogenic flux.

\subsection{Effects of CP on Glucose Uptake Related Gene Expression in the Skeletal Muscle}

Changes in mRNA expression of GLUT4, HK2 and PPAR $\gamma$ in femoral muscle by sample treatment were analyzed using a qRT-PCR. GLUT4 gene expression was significantly upregulated by metformin and CP treatment $(p<0.05$, Figure $4 \mathrm{~A})$.

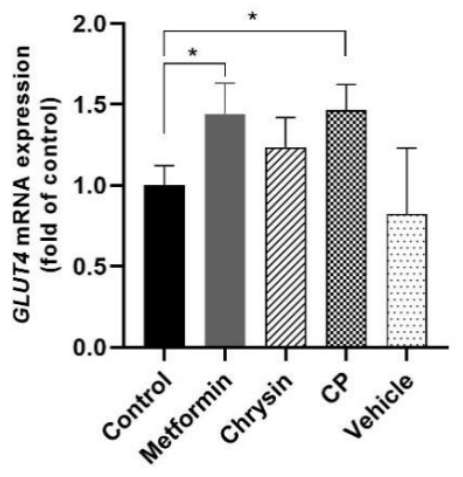

(A)

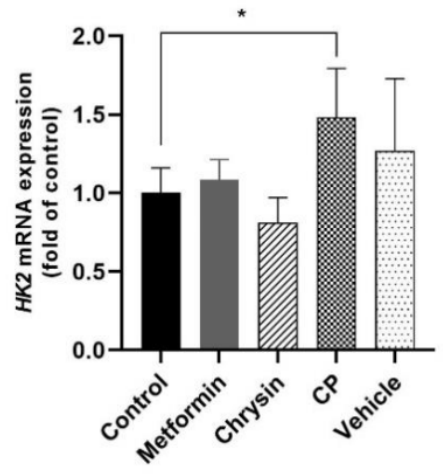

(B)

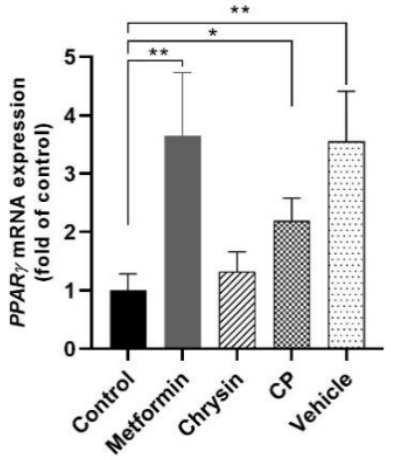

(C)

Figure 4. The effects of $\mathrm{CP}$ on the glucose uptake related gene expression in the skeletal muscle of $\mathrm{db} / \mathrm{db}$ mice. (A) GLUT4, (B) HK2, and (C) PPAR $\gamma$ GLUT4, glucose transporter 4; HK2, hexokinase 2 ; PPAR $\gamma$, peroxisome proliferator-activated receptor $\gamma ; \mathrm{CP}$, chrysin-loaded phytosomes. Each value represents mean \pm standard error $(n=8) .{ }^{*} p<0.05,{ }^{* *} p<0.01$ compared with the control group.

HK2 gene expression increased by 1.5 -fold in the $\mathrm{CP}$ group compared to the control group $(p<0.05$, Figure 4B). PPAR $\gamma$ gene expression was significantly increased in the metformin, CP, and vehicle groups ( $p<0.05$, Figure 4 C). Jeong et al. [40] reported that ginsenoside Rh4, Rg5, and Rk1 in black ginseng extract significantly upregulated PPAR $\gamma$ gene expression in muscle and improved insulin resistance in $\mathrm{db} / \mathrm{db}$ mice. GLUT4 is a dominant insulin responsive glucose transporter in skeletal muscle. It promotes the active transport of glucose across the plasma membrane and HK2 contributed to glucose disposal of skeletal muscle by maintaining the glucose concentration gradient within the cell. Epinephrine and insulin transcriptionally regulated these glucose utilization steps in skeletal muscles [41]. Reduced GLUT4 expression and impaired insulin signaling lead to incomplete glucose tolerance (IGT) and hyperglycemia in type 2 DM [42]. Downregulated GLUT4 mRNA and protein expression in skeletal muscle are the main possible reasons for insulin resistance and is often observed in $\mathrm{db} / \mathrm{db}$ mice $[43,44]$. GLUT4 overexpression in the skeletal muscle of $\mathrm{db} / \mathrm{db}$ mice restored plasma glucose disposal and improved insulin sensitivity [45].

Oral supplementation of chrysin $(50 \mathrm{mg} / \mathrm{kg}$ ) resulted in an antidiabetic effect in diabetic athymic nude mice induced by nicotinamide injection [46]. However, a similar effect was not seen in this investigation. OGTT and changes in serum inflammatory cytokine production were analyzed under acute and subacute diabetic conditions (50 mg/kg, 10 days) using athymic nude diabetic mice in the previous study [46]. Unfortunately, they did not provide detailed information regarding the mechanisms of antidiabetic effect. Different animal models and experimental periods might affect the results even though the exact reasons for this discrepancy are not clear. 
PPAR $\gamma$ exerts an insulin sensitizing effect and dysfunction of PPAR $\gamma$ causes insulin resistance and DM in humans [47]. PPAR $\gamma$ activation through ligand binding of thiazolidinediones enhanced insulin sensitivity in type 2 diabetic patients [48]. Furthermore, PPAR $\gamma$-agonist also stimulated insulin-mediated suppression of gluconeogenesis in the liver [49]. In our previous investigation, CP significantly increased glucose uptake in C2C12 myotubes by activating PPAR $\gamma$ and GLUT4 [18]. $\mathrm{CP}$-mediated glucose uptake promoting the effect observed in skeletal muscle cells was confirmed in $\mathrm{db} / \mathrm{db}$ mice. $\mathrm{CP}$ promoted glucose utilization in skeletal muscles by activating glucose uptake-related gene expression in the skeletal muscle.

\subsection{Effects of CP on GLUT4 Plasma Translocation in db/db Mice}

GLUT4 normally located in the cytoplasm as vesicles in the skeletal muscle and translocated to plasma membrane in response to insulin or AMPK stimulation. Insulin resistance in skeletal reduced plasma GLUT4 translocation and glycogen synthesis in type $2 \mathrm{DM}$ [50]. In order to confirm CP treatment leading to improved GLUT4 translocation, immunoblotting of plasma membrane GLUT4 was carried out. Plasma translocations of GLUT4 were increased by 1.6-fold in the CP group in the skeletal muscle of $\mathrm{db} / \mathrm{db}$ mice compared to the control group ( $p<0.05$, Figure 5$)$. This result indicates that the CP-induced improvement of insulin resistance in the $\mathrm{db} / \mathrm{db}$ mice was probably caused by increased GLUT 4 translocation and insulin sensitivity in the skeletal muscle.

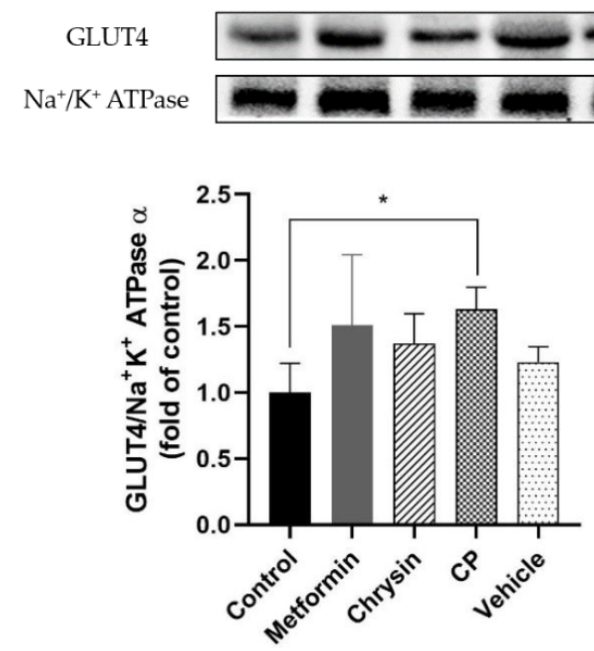

Figure 5. The effects of CP on the GLUT4 plasma translocation in the skeletal muscle of db/db mice. Each value represents mean \pm standard error $(n=8) .{ }^{*} p<0.5$ compared to the control group.

\section{Materials and Methods}

\subsection{Materials}

Egg phospholipid (EPL) was kindly provided by Doosan Corporation (Seoul, Korea). Chrysin and all other reagents were purchased from Sigma-Aldrich Inc. (St. Louis, MO, USA). The hemoglobin $\mathrm{A} 1 \mathrm{c}(\mathrm{HbA} 1 \mathrm{c})$, insulin, and leptin quantification kits were purchased from Crystal Chem (Downer Grove, IL, USA). Triacylglycerol (TG) and total cholesterol (TC) quantification kits were purchased from Abcam (Cambridge, MA, USA). Taqman ${ }^{\circledR}$ Universal Mastermix, Taqman ${ }^{\circledR}$ probes and the high capacity RNA-to-cDNA kit were purchased from Applied Biosystems (Foster City, CA, USA).

\subsection{Preparation of $C P$}

The CP was prepared using the solvent evaporation method as previously described [15]. Briefly, chrysin and EPL were dissolved in tetrahydrofuran at a molar ratio of $1: 3$, placed in a $40{ }^{\circ} \mathrm{C}$ water bath, and stirred for $4 \mathrm{~h}$. Empty phytosomes (vehicle) were made by excluding chrysin. 


\subsection{Animals and Diets}

Male C57BLKS/J-db/db mice (5 weeks old) were purchased from Central Lab, Animal Inc. (Seoul, Korea). Four mice were housed per cage at $22 \pm 2{ }^{\circ} \mathrm{C}$ and $50 \pm 10 \%$ relative humidity, with a $12 \mathrm{~h}$ light:dark cycle. After 1 week acclimatization period, the mice were randomly divided into six groups (8 mice in each group): (1) non diabetes group ( $\mathrm{m}+/ \mathrm{db}, \mathrm{C} 57 / \mathrm{BLK} / \mathrm{J} \mathrm{m}+/ \mathrm{db})$, (2) diabetes control group (Control, C57/BLK/J db/db), (3) positive control group (Metformin, C57/BLK/J db/db + $200 \mathrm{mg}$ metformin/kg), (4) db/db + chrysin group (Chrysin, C57/BLK/J db/db + $100 \mathrm{mg}$ chrysin/kg), (5) db/db + $\mathrm{CP}(\mathrm{CP}, \mathrm{C} 57 / \mathrm{BLK} / \mathrm{J} \mathrm{db} / \mathrm{db}+100 \mathrm{mg}$ chrysin equivalent/kg), and (6) db/db + vehicle group (Vehicle, $\mathrm{C} 57 / \mathrm{BLK} / \mathrm{J} \mathrm{db} / \mathrm{db}+\mathrm{EPL}$ used for CP preparation). The samples containing the indicated dosage were dispersed in PBS and daily through oral gavage for 9 weeks. The dosage of chrysin to be administered was determined based on a chemopreventive study of chrysin [51]. The chrysin content in CP was quantified using HPLC as previously described [18]. Animals had free access to standard chow diet (SAFE, Villemoison-sur-Orge, France) and tap water. Body weight and food intake were recorded weekly. Permission for the animal experiments was granted by Kookmin University Institutional Animal Care and Use Committee (KMUIACUC-2019-01) and continued for 9 weeks.

\subsection{Blood Biochemical Analysis}

The mice were sacrificed after $15 \mathrm{~h}$ of fasting and blood samples were collected. Serum was obtained by centrifuging the blood at $2000 \times \mathrm{g}$ for $15 \mathrm{~min}$ at $4{ }^{\circ} \mathrm{C}$. Serum alanine aminotransferase (ALT), aspartate aminotransferase (AST), TG, TC, and high-density lipoprotein cholesterol (HDL-c), were measured using a blood analyzer (FUJI DRI-CHEM 3500i, Fujifilm, Tokyo, Japan). Low-density lipoprotein cholesterol (LDL-c) was calculated by applying the Friedewald equation [52]. HbA1c levels in whole blood were determined using an assay kit (Crystal Chem, Downer Grove, IL, USA). Serum insulin and leptin levels in serum were determined using assay kits (Crystal Chem, Downer Grove, IL, USA) according to the manufacturers' instructions. Homeostasis model assessment of insulin resistance (HOMA-IR) index was calculated as follows: HOMA-IR $=$ fasting insulin $(\mu \mathrm{U} / \mathrm{mL}) \times$ fasting blood glucose $(\mathrm{mmol} / \mathrm{L}) / 22.5$ [53].

\subsection{Oral Glucose Tolerance Test (OGTT)}

OGTT was conducted at week 7 after $12 \mathrm{~h}$ fasting using a slightly modified method described by Kim et al. [19]. Blood was collected from the tail veins of mice at $0,15,30,60,90$, and 120 min after oral administration of glucose $(1.5 \mathrm{~g} / \mathrm{kg}$ BW). Blood glucose levels were measured using a blood glucose analyzer (Allmedicus, Seoul, Korea). The area under the curve (AUC) for the experimental groups was calculated as described by Pruessner et al. [54].

\subsection{RNA Extraction and Quantitative Real-Time PCR}

Total RNA was extracted from the liver and femoral muscle using QIAzol ${ }^{\circledR}$ lysis reagent (QIAGEN, Hilden, Germany) according to the manufacturer's instruction. Single-stranded cDNA was synthesized using a cDNA kit (Applied Biosystems) and qRT-PCR was performed as described elsewhere [55]. Relative quantification of target mRNA (glucose-6-phosphatase (G6Pase) phosphoenolpyruvate carboxykinase (PEPCK), and hexokinase 2 (HK2) in the liver; glucose transporter 4 (GLUT4), hexokinase 2 (HK2), peroxisome proliferator-activated receptor $\gamma$ (PPAR $\gamma)$ in femoral muscle) was performed using the comparative CT method by normalizing to the value of the housekeeping gene $\beta$-actin. All experiments were conducted in triplicate.

\subsection{GLUT4 Translocation on the Plasma Membrane of Femoral Muscle}

The level of GLUT4 translocation on the plasma membrane of femoral muscle was analyzed using a plasma membrane extraction kit (Abcam, Cambridge, MA, USA) according to a previously published 
method [56]. The relative intensity of GLUT4 band was normalized to Na+/K+-ATPase and quantified using Image Lab 5.1 software package (BioRad, Hercules, CA, USA).

\subsection{Statistical Analysis}

All data were presented as mean \pm standard error. Statistical analysis was performed using Prism 8 (GraphPad Software, Inc., CA, USA). All data were compared using a one-way ANOVA test. A Fisher's least significant difference (LSD) multiple comparisons test was used to compare the control and treatment groups. In statistical analysis, a $p$-value of $<0.05,<0.01,<0.001$ was considered as statistically significant.

\section{Conclusions}

CP supplementation significantly improved FBG levels and glucose tolerance in $\mathrm{db} / \mathrm{db}$ mice compared with the control group. The insulin levels of $\mathrm{CP}$-treated $\mathrm{db} / \mathrm{db}$ mice were significantly decreased and the surrogate biomarker for insulin resistance, HOMA-IR, was consistently reduced. $\mathrm{CP}$ inhibited gluconeogenesis by down regulation of PEPCK and promoted glucose uptake in the skeletal muscle of $\mathrm{db} / \mathrm{db}$ mice. The insulin levels of $\mathrm{CP}$-treated $\mathrm{db} / \mathrm{db}$ mice were significantly decreased and the surrogate biomarker for insulin resistance, especially HOMA-IR level, was lower than the chrysin group. $\mathrm{CP}$ inhibited gluconeogenesis by down regulating PEPCK and promoted glucose uptake in the skeletal muscle of $\mathrm{db} / \mathrm{db}$ mice. $\mathrm{CP}$ showed greater antidiabetic performance compared with the control by ameliorating insulin resistance in $\mathrm{db} / \mathrm{db}$ mice. $\mathrm{CP}$ also demonstrated an additional effect not observed with chrysin. The antidiabetic effect of $\mathrm{CP}$ was probably due to increased bioavailability of the nano-sized chrysin-loaded phytosome formulation.

Author Contributions: Conceptualization, project administration, funding acquisition, writing and editing-J.-Y.I.; methodology, investigation, writing original draft preparation-S.-m.K. All authors have read and agreed to the published version of the manuscript.

Funding: The research was funded by Ministry of Science, ICT and Future Planning, Korea (grant number 2017R1A2B24009715).

Acknowledgments: This research was supported by Basic Science Research Program through the National Research Foundation of Korea (NRF) funded by the Ministry of Science, ICT and Future Planning (2017R1A2B24009715).

Conflicts of Interest: The authors declare no conflict of interest.

$\begin{array}{ll}\text { Abbreviations } \\ \text { DM } & \text { Diabetes mellitus } \\ \text { HbA1c } & \text { Hemoglobin A1c } \\ \text { TG } & \text { Triacylglycerol } \\ \text { TC } & \text { Total cholesterol } \\ \text { FGB } & \text { Fasting blood glucose level } \\ \text { ALT } & \text { Serum alanine aminotransferase } \\ \text { AST } & \text { Aspartate aminotransferase } \\ \text { HDL-c } & \text { High-density lipoprotein cholesterol } \\ \text { LDL-c } & \text { Low-density lipoprotein cholesterol } \\ \text { AUC } & \text { Area under the curve } \\ \text { OGTT } & \text { Oral glucose tolerance test } \\ \text { G6 Pase } & \text { Glucose-6-phosphatase } \\ \text { PEPCK } & \text { Phosphoenolpyruvate carboxykinase } \\ \text { HK2 } & \text { Hexokinase 2 } \\ \text { GLUT4 } & \text { Glucose transporter 4 } \\ \text { PPAR } \gamma & \text { Peroxisome proliferator-activated receptor } \gamma\end{array}$




\section{References}

1. Bavenholm, P.N.; Pigon, J.; Ostenson, C.G.; Efendic, S. Insulin sensitivity of suppression of endogenous glucose production is the single most important determinant of glucose tolerance. Diabetes 2001, 50, 1449-1454. [CrossRef]

2. Tripathi, B.K.; Srivastava, A.K. Diabetes mellitus: Complications and therapeutics. Med. Sci. Monit. Basic Res. 2006, 12, RA130-RA147.

3. Fang, J.-Y.; Lin, C.-H.; Huang, T.-H.; Chuang, S.-Y. In vivo rodent models of type 2 diabetes and their usefulness for evaluating flavonoid bioactivity. Nutrients 2019, 11, 530. [CrossRef]

4. Wedick, N.M.; Pan, A.; Cassidy, A.; Rimm, E.B.; Sampson, L.; Rosner, B.; Willet, W.; Hu, F.B.; Sun, Q.; Van Dam, R.M. Dietary flavonoid intakes and risk of type 2 diabetes in US men and women. Am. J. Clin. Nutr. 2012, 95, 925-933. [CrossRef] [PubMed]

5. Yeon, J.-Y.; Bae, Y.J.; Kim, E.-Y.; Lee, E.-J. Association between flavonoid intake and diabetes risk among the Koreans. Clin. Chim. Acta 2015, 439, 225-230. [CrossRef] [PubMed]

6. Wang, T.; Li, Q.; Bi, K. Bioactive flavonoids in medicinal plants: Structure, activity and biological fate. Asian J. Pharm. Sci. 2018, 13, 12-23. [CrossRef] [PubMed]

7. Ahad, A.; Ganai, A.A.; Mujeeb, M.; Siddiqui, W.A. Chrysin, an anti-inflammatory molecule, abrogates renal dysfunction in type 2 diabetic rats. Toxicol. Appl. Pharmacol. 2014, 279, 1-7. [CrossRef]

8. Li, R.; Zang, A.; Zhang, L.; Zhang, H.; Zhao, L.; Qi, Z.; Wang, H. Chrysin ameliorates diabetes-associated cognitive deficits in Wistar rats. Neurol. Sci. 2014, 35, 1527-1532. [CrossRef]

9. El-Bassossy, H.M.; Abo-Warda, S.M.; Fahmy, A. Chrysin and luteolin alleviate vascular complications associated with insulin resistance mainly through PPAR- $\gamma$ activation. Am. J. Chin. Med. 2014, 42, 1153-1167. [CrossRef]

10. Andrade, N.; Andrade, S.; Silva, C.; Rodrigues, I.; Guardão, L.; Guimarães, J.T.; Martel, F. Chronic consumption of the dietary polyphenol chrysin attenuates metabolic disease in fructose-fed rats. Eur. J. Nutr. 2020, 59, 151-165. [CrossRef]

11. Goes, A.T.R.; Jesse, C.R.; Antunes, M.S.; Ladd, F.V.L.; Ladd, A.A.B.L.; Luchese, C.; Paroul, N.; Boeira, S.P. Protective role of chrysin on 6-hydroxydopamine-induced neurodegeneration a mouse model of Parkinson's disease: Involvement of neuroinflammation and neurotrophins. Chem. Biol. Interact. 2018, 279, 111-120. [CrossRef] [PubMed]

12. Ross, J.A.; Kasum, C.K. Dietary flavonoids: Bioavailability, metabolic effects and safety. Ann. Rev. Nutr. 2002, 22, 19-34. [CrossRef] [PubMed]

13. Walle, T.; Otake, Y.; Brubaker, J.A.; Walle, U.K.; Halushka, P.V. Disposition and metabolism of the flavonoid chrysin in normal volunteers. Br. J. Clin. Pharmacol. 2001, 51, 143-146. [PubMed]

14. Andrade, N.; Marques, C.; Andrade, S.; Silva, C.; Rodrigues, I.; Guardao, L.; Guimaraes, J.T.; Keating, E.; Calhau, C.; Martel, F. Effect of chrysin on changes in intestinal environment and microbiome induced by fructose-feeding in rats. Food Funct. 2019, 10, 4566-4576. [CrossRef] [PubMed]

15. Li, J.; Wang, X.; Zhang, T.; Wang, C.; Huang, Z.; Luo, X.; Deng, Y. A review on phospholipids and their main applications in drug delivery systems. Asian J. Pharm. Sci. 2015, 10, 81-98. [CrossRef]

16. Mancini, S.; Nardo, L.; Gregiri, M.; Ribeiro, I.; Mantegazza, F.; Delerue-Matos, C.; Masserini, M.; Grosso, G. Functionalized liposomes and phytosomes loading Annona murcata L. aqueous extract: Potential nanoshuttles for brain-delivery of phenolic compounds. Phytomedicine 2018, 42, 233-244. [CrossRef]

17. Rani, A.; Kumar, S.; Khar, R.K. Casuarina equisetifolia extract loaded phytosomes: Optimization, characterization and in vivo evaluation of antidiabetic and antihyperlipidemic activities in Wistar rats. Drug Deliv. Lett. 2019, 9, 116-133. [CrossRef]

18. Kim, S.-M.; Jung, J.-I.; Chai, C.; Imm, J.-Y. Characteristics and glucose uptake promoting effect of chrysin-loaded phytosomes prepared with different phospholipid matrices. Nutrients 2019, 11, 2549. [CrossRef]

19. Miyamoto, S.; Yasui, Y.; Ohigashi, H.; Tanaka, T.; Murakami, A. Dietary flavonoids suppress azoxymethane-induced colonic preneoplastic lesions in male $\mathrm{C} 57 \mathrm{BL} / \mathrm{KsJ}-\mathrm{db} / \mathrm{db}$ mice. Chem. Biol. Interact. 2010, 183, 276-283. [CrossRef]

20. Thapa, B.; Walia, A. Liver function test and their interpretation. Indian J. Pediatr. 2007, 74, 663-671. [CrossRef]

21. Sirovina, D.; Oršolić, N.; Končić, M.Z.; Kovačević, G.; Benković, V.; Gregorović, G. Quercetin vs chrysin: Effect on liver histopathology in diabetic mice. Hum. Exp. Toxicol. 2013, 32, 1058-1066. [CrossRef] [PubMed] 
22. Lee, H.S.; Nam, Y.; Chung, Y.H.; Kim, H.R.; Park, E.S.; Chung, S.J.; Kim, J.Y.; Sohn, U.D.; Kim, H.C.; Oh, K.W.; et al. Beneficial effects of phosphatidylcholine on high-fat diet-induced obesity, hyperlipidemia and fatty liver in mice. Life Sci. 2014, 118, 7-14. [CrossRef] [PubMed]

23. Jiang, Y.; Noh, S.K.; Koo, S.I. Egg phosphatidylcholine decreases the lymphatic absorption of cholesterol in rats. J. Nutr. 2001, 131, 2358-2363. [CrossRef]

24. Norris, G.H.; Jiang, C.; Ryan, J.; Porter, C.M.; Blesso, C.N. Milk sphingomyelin improves lipid metabolism and alters gut microbiota in high fat diet-fed mice. J. Nutr. Biochem. 2016, 30, 93-101. [CrossRef] [PubMed]

25. Rabe, K.; Lehrke, M.; Parhofer, K.G.; Broedl, U.C. Adipokines and insulin resistance. Mol. Med. 2008, 14, 741-751. [CrossRef] [PubMed]

26. Takahashi, S.; Uchino, H.; Shimizu, T.; Kanazawa, A.; Tamura, Y.; Sakai, K.; Tanaka, Y. Comparison of glycated albumin (GA) and glycated hemoglobin (HbA1c) in type 2 diabetic patients: Usefulness of GA for evaluation of short-term changes in glycemic control. Endocr. J. 2007, 54, 139-144. [CrossRef] [PubMed]

27. Bennett, C.M.; Guo, M.; Dharmage, S.C. HbA1C as a screening tool for detection of Type 2 diabetes: A systematic review. Diabet. Med. 2007, 24, 333-343. [CrossRef]

28. Kang, Y.; Lee, M.; Song, H.; Hyun, Y.; Cha, J.; Ko, J.; Cha, D. Aliskiren improves insulin resistance and ameliorates diabetic vascular complications in db/db mice. Nephrol. Dial. Transplant. 2011, 26, 1194-1204. [CrossRef]

29. Chi, C.; Zhang, C.; Liu, Y.; Nie, H.; Zhou, J.; Ding, Y. Phytosome-nanosuspensions for silybin-phospholipid complex with increased bioavailability and hepatoprotection efficacy. Eur. J. Pharm. Sci. 2020, 144, 105212. [CrossRef]

30. Riva, A.; Ronchi, M.; Petrangolini, G.; Bosiso, S.; Allegrini, P. Improved oral absorption of quercetin phytosome ${ }^{\circledR}$, a new delivery system based on food grade lecithin. Eur. J. Drug. Metab. Pharmacokinet. 2019, 44, 169-177. [CrossRef]

31. Basu, A.; Basu, R.; Shah, P.; Vella, A.; Johnson, C.M.; Nair, K.S.; Jensen, M.D.; Schwenk, W.F.; Rizza, R.A. Type 2 diabetes impairs splanchnic uptake of glucose but does not alter intestinal glucose absorption during enteral glucose feeding: Additional evidence for a defect in hepatic glucokinase activity. Diabetes 2001, 50, 1351-1362. [CrossRef] [PubMed]

32. Barthel, A.; Schmoll, D. Novel concepts in insulin regulation of hepatic gluconeogenesis. Am. J. Physiol. Endocrinol. Metab. 2003, 285, E685-E692. [CrossRef] [PubMed]

33. Hundal, R.S.; Krssak, M.; Dufour, S.; Laurent, D.; Lebon, V.; Chandramouli, V.; Inzucchi, S.E.; Schumann, W.C.; Petersen, F.F.; Landau, B.R.; et al. Mechanism by which metformin reduces glucose production in type 2 diabetes. Diabetes 2000, 49, 2063-2069. [CrossRef] [PubMed]

34. Li, M.; Dang, Y.; Li, Q.; Zhou, W.; Zuo, J.; Yao, Z.; Zhang, L.; Ji, G. Berberine alleviates hyperglycemia by targeting hepatic glucokinase in diabetic db/db mice. Sci. Rep. 2019, 9, 8003. [CrossRef] [PubMed]

35. Cárdenas, M.L.; Cornish-Bowden, A.; Ureta, T. Evolution and regulatory role of the hexokinases. Biochim. Biophys. Acta Mol. Cell Res. 1998, 1401, 242-264. [CrossRef]

36. Postic, C.; Shiota, M.; Niswender, K.D.; Jetton, T.L.; Chen, Y.; Moates, J.M.; Magnuson, M.A. Dual roles for glucokinase in glucose homeostasis as determined by liver and pancreatic $\beta$ cell-specific gene knock-outs using Cre recombinase. J. Biol. 1999, 274, 305-315. [CrossRef]

37. Ramnanan, C.J.; Edgerton, D.S.; Cherrington, A.D. The role of insulin in the regulation of PEPCK and gluconeogenesis in vivo. US Endocrinol. 2010, 5, 34-39. [CrossRef]

38. Michael, M.D.; Kulkarni, R.N.; Postic, C.; Previs, S.F.; Shulman, G.I.; Magnuson, M.A.; Kahn, C.R. Loss of insulin signaling in hepatocytes leads to severe insulin resistance and progressive hepatic dysfunction. Mol. Cell 2000, 6, 87-97. [CrossRef]

39. Park, H.J.; Jung, U.J.; Cho, S.J.; Jung, H.K.; Shim, S.; Choi, M.S. Citrus unshiu peel extract ameliorates hyperglycemia and hepatic steatosis by altering inflammation and hepatic glucose-and lipid-regulating enzymes in db/db mice. J. Nutr. Biochem. 2013, 24, 419-427. [CrossRef]

40. Jeong, Y.J.; Hwang, M.J.; Hong, C.O.; Yoo, D.S.; Kim, J.S.; Kim, D.Y.; Lee, K.W. Anti-hyperglycemic and hypolipidemic effects of black ginseng extract containing increased Rh4, Rg5, and Rk1 content in muscle and liver of type 2 diabetic db/db mice. Food. Sci. Biotechnol. 2020, 29, 1101-1112. [CrossRef]

41. Jones, J.P.; Dohm, G.L. Regulation of glucose transporter GLUT-4 and hexokinase II gene transcription by insulin and epinephrine. Am. J. Physiol. 1997, 273, E682-E687. [CrossRef] [PubMed] 
42. Watson, R.T.; Pessin, J.E. Intracellular organization of insulin signaling and GLUT4 translocation. Recent Prog. Horm. Res. 2001, 56, 175-193. [CrossRef] [PubMed]

43. Burcelin, R.; Crivelli, V.; Perrin, C.; Da Costa, A.; Mu, J.; Kahn, B.B.; Birnbaum, M.J.; Kahn, C.R.; Vollenweider, P.; Thorens, B. GLUT4, AMP kinase, but not the insulin receptor, are required for hepatoportal glucose sensor-stimulated muscle glucose utilization. J. Clin. Investig. 2003, 111, 1555-1562. [CrossRef] [PubMed]

44. Shao, J.; Yamashita, H.; Qiao, L.; Friedman, J.E. Decreased Akt kinase activity and insulin resistance in C57BL/KsJ-Leprdb/db mice. J. Endocrinol. 2000, 167, 107-115. [CrossRef]

45. Gibbs, E.M.; Stock, J.L.; McCoid, S.C.; Stukenbrok, H.A.; Pessin, J.E.; Stevenson, R.W.; McNeish, J.D. Glycemic improvement in diabetic $\mathrm{db} / \mathrm{db}$ mice by overexpression of the human insulin-regulatable glucose transporter (GLUT4). J. Clin. Investig. 1995, 95, 1512-1518. [CrossRef]

46. Ramírez-Espinosa, J.J.; Saldaña-Ríos, J.; García-Jiménez, S.; Villalobos-Molina, R.; Ávila-Villarreal, G.; Rodríguez-Ocampo, A.N.; Bernal-Fernández, G.; Estrada-Soto, D. Chrysin induces antidiabetic, antidyslipidemic and anti-inflammatory effects in Athymic nude diabetic mice. Molecules 2018, $23,67$. [CrossRef]

47. Barroso, I.; Gurnell, M.; Crowley, V.E.F.; Agostini, M.; Schwabe, J.W.; Soos, M.A.; Maslen, G.L.; Williams, T.D.M.; Lewis, H.; Schafer, A.J.; et al. Dominant negative mutations in human PPAR gamma associated with severe insulin resistance, diabetes mellitus and hypertension. Nature 1999, 402, 880-883. [CrossRef]

48. Raskin, P.; Rappaport, E.B.; Cole, S.T.; Yan, Y.; Patwardhan, R.; Freed, M.I. Rosiglitazone short-term monotherapy lowers fasting and post-prandial glucose in patients with type 2 diabetes. Diabetologia 2000, 43, 278-284. [CrossRef]

49. Way, J.M.; Harrington, W.W.; Brown, K.K.; Gottschalk, W.K.; Sundseth, S.S.; Mansfield, T.A.; Ramachandran, R.K.; Willson, T.M.; Kliewer, S.A. Comprehensive messenger ribonucleic acid profiling reveals that peroxisome proliferator-activated receptor gamma activation has coordinate effects on gene expression in multiple insulin-sensitive tissues. Endocrinology 2001, 142, 1269-1277. [CrossRef]

50. Cline, G.W.; Petersen, K.F.; Krssak, M.; Shen, J.; Hundal, R.S.; Trajanoski, Z.; Inzucchi, S.; Dresner, A.; Rothman, D.L.; Shulman, G.I. Impaired glucose transport as a cause of decreased insulin-stimulated muscle glycogen synthesis in type 2 diabetes. N. Engl. J. Med. 1999, 341, 240-246. [CrossRef]

51. Eshvendar, R.K.; Lakshmi, N.B.; Chandana, C.B.; Rajaram, M.M.; Vicky, D.; Mukesh, K.B.; Ramana, R.M.; Suseela, M.; Ranadeep, G. Chemopreventive effect of chrysin, a dietary flavone against benzo(a)pyrene induced lung carcinogenesis in Swiss albino mice. Pharmacol. Rep. 2016, 68, 310-318.

52. Friedewald, W.T.; Levy, R.I.; Fredrickson, D.S. Estimation of the concentration of low-density lipoprotein cholesterol in plasma, without use of the preparative ultracentrifuge. Clin. Chem. 1972, 18, 499-502. [CrossRef] [PubMed]

53. Matthews, D.R.; Hosker, J.P.; Rudenski, A.S.; Naylor, B.A.; Treacher, D.F.; Turner, R.C. Homeostasis model assessment: Insulin resistance and $\beta$-cell function from fasting plasma glucose and insulin concentrations in man. Diabetologia 1985, 28, 412-419. [CrossRef] [PubMed]

54. Pruessner, J.C.; Kirschbaum, C.; Meinlschmid, G.; Hellharmmer, D.H. Two formulas for computation of the area under the curve represent measures of total hormone concentration versus time-dependent change. Psychoneuroendocrinology 2003, 28, 916-931. [CrossRef]

55. Kim, C.; Lee, J.; Kim, M.B.; Hwang, J.K. Hypoglycemic effect of whole grain diet in C57BL/KsJ-db/db mice by activating PI3K/Akt and AMPK pathways. Food. Sci. Biotechnol. 2019, 28, 895-905. [CrossRef]

56. Yoon, H.J.; Bang, M.H.; Kim, H.; Imm, J.Y. Improvement of palmitate-induced insulin resistance in C2C12 skeletal muscle cells using Platycodon grandiflorum seed extracts. Food Biosci. 2018, 25, 61-67. [CrossRef]

Publisher's Note: MDPI stays neutral with regard to jurisdictional claims in published maps and institutional affiliations. 